\title{
"COMO É POSSIIVEL QUE VOCÊ TENHA UM PH.D. E AINDA NÃO SAIBA CORTAR UMA COSIELA EM PÉ?" SIDNEY MINIZ E A ANTROPOLOGIA DA ALLMENTAÇÃOO
}

\section{Ceres Gomes Víctora \\ Maria Eunice Maciel \\ Universidade Federal do Rio Grande do Sul - Brasil}

O nome de Sidney Mintz é sobejamente conhecido entre os antropólogos de várias gerações. Grande foi e é sua importância na disciplina desde a segunda metade do século XX, tendo enriquecido, significativamente, o debate antropológico. Suas pesquisas têm motivado fecundas perspectivas, tanto no que se refere às culturas do Caribe quanto à área conhecida como antropologia da alimentação no Brasil.

No primeiro caso, o seu trabalho de campo na região do Caribe iniciou-se em 1948, primeiramente em Porto Rico e na Jamaica, e subsequentemente no Haiti. Suas pesquisas contemplam de forma abrangente a complexidade de sociedades marcadas por uma história de trabalho forçado e escravidão imposta pela colonização europeia nas Américas e pelo modo de produção da cana-de-açúcar. Seu evidente interesse pela história e pela economia política da região motivou a escrita e a edição de dezenas de livros e centenas de artigos que influenciaram antropólogos e historiadores em todo o mundo desde meados do século XX. Entre os seus livros mais conhecidos encontra-se Sweetness and power: the place of sugar in modern society (Mintz, 1985), no qual analisa um conjunto de conexões históricas, econômicas e sociais envolvidas na produção e no consumo de um produto que se tornou importantíssimo na dieta alimentar contemporânea.

Já no segundo caso, a antropologia da alimentação - que nos Estados Unidos é conhecida como "anthropology of food" - aparece como um interesse, em certa medida, decorrente do primeiro. Ao escrever extensamente sobre 
um alimento específico, no caso o açúcar, ele passa gradativamente ao estudo de outros alimentos, refletindo também sobre a questão mais geral da relação dos homens com a comida.

Diz o autor em seu website:

Não tivemos nenhuma comida natural desde que nos tornamos plenamente humanos, exceto, talvez, o leite materno. Os alimentos de diferentes povos, moldados pelo habitat e pela história, tornar-se-iam um marco vivo de diferença, símbolos de pertença e de exclusão. (tradução nossa). ${ }^{1}$

Muito pouco de sua grande e influente obra foi traduzida para o português, fazendo com que sua difusão, no Brasil, seja limitada. De fato, temos apenas à disposição em língua portuguesa, o artigo "Encontrando Taso, me descobrindo" (Mintz, 1984) - publicado na Revista de Ciências Sociais - em 1984; O poder amargo do açúcar: produtores escravizados, consumidores proletarizados (Mintz, 2003) - uma coletânea de importantes trabalhos publicada pela Universidade Federal de Pernambuco organizada por Christine Rufino Dabat - em 2003; e "Comida e antropologia: uma breve revisão" (Mintz, 2001), sua conferência apresentada na Reunião da Anpocs de 2000 e publicada pela Revista Brasileira de Ciências Sociais (disponível on-line).

Suas reflexões sobre uma região com um passado e um presente açucareiro, embora tratando do Caribe, atingem diretamente as discussões sobre esse tema no Brasil. Tanto assim que Mintz é referência importantíssima para nós, sendo citado em inúmeros estudos sobre o açúcar e seu modo de produção no Nordeste brasileiro.

Sempre partindo de uma perspectiva histórica, os livros de sua autoria (ou que organizou), como Tasting food, tasting freedom: excursions into eating, power, and the past (Mintz, 1996) e The world of soy (Du Bois; Tan; Mintz, 2008), analisam mudanças nos hábitos e na produção de alimentos específicos observáveis em diferentes partes do mundo ao longo da história. Para ele, ao estudarmos questões aparentemente específicas de certos alimentos, não podemos perder de vista o objetivo maior da antropologia que é o

1 Ver http://sidneymintz.net.

Horizontes Antropológicos, Porto Alegre, ano 18, n. 38, p. 373-379, jul./dez. 2012 
de entender as dinâmicas, as políticas, as economias e as relações de poder que se produzem nas histórias das diferentes sociedades. Na entrevista realizada para este volume de Horizontes Antropológicos, ele refere: "Para antropólogos, esquecer o legado dos últimos cinco séculos é esquecer o lugar do imperialismo e do colonialismo na formação do mundo que a minha geração herdou. Acredito que essas são coisas que nós precisamos ter em mente para explicar qualquer fenômeno contemporâneo."

E é esse sentido, profundamente político da antropologia, que Mintz ressalta ao falar do seu trabalho e sobre o fazer antropológico.

Sidney Mintz estudou na Columbia University sob a supervisão de Julian Steward e Ruth Benedict, assim como outros alunos dessa fase que vieram a ser importantes antropólogos, tais como Marvin Harris, Eric Wolf, Morton Fried, Stanley Diamond, Robert Manners e Robert F. Murphy.

Mintz construiu sua carreira na Universidade de Yale, onde ingressou em 1951, permanecendo até 1974. Em 1975, foi para a Johns Hopkins University, onde ajudou a estabelecer o departamento de antropologia. Foi também professor/pesquisador visitante (visiting lecturer) no Massachusetts Institute of Technology, Princeton, Berkeley, na École Pratique des Hautes Études e no Collège de France, Paris, além de diversos outros lugares, tais como Nova Zelândia, Austrália e Hong Kong. Em 1992 foi estabelecida a honraria Sidney W. Mintz Lecture, uma conferência promovida anualmente pelo departamento de antropologia da Johns Hopkins University no outono, para a qual é convidado um palestrante cujas pesquisas tenham sido influenciadas por sua extensa obra.

Dentre as suas publicações encontramos, por exemplo, em 1956, seu estudo de uma aldeia de trabalhadores na cana-de-açúcar, que foi incluído na obra The people of Puerto Rico, organizada por Julian Steward (Mintz, 1956). Publicou também várias obras sobre o campesinato na região do Caribe, tais como Worker in the cane (Mintz, 1960) e Caribbean transformations (Mintz, 1974). Com Richard Price, Mintz publicou em 1976 o texto The birth of African-American culture (Mintz; Price, 1992), que se tornou um marco nos estudos sobre o tema. Da mesma forma, Caribbean contours, de 1985, com Sally Price, também é tido como referência (Mintz; Price, 1985).

Como referimos, em sua obra, história e antropologia são aproximadas. Pode-se mesmo dizer que Mintz realiza uma "etnografia com uma perspectiva histórica", fornecendo perspectivas analíticas capazes de articular as assim 
chamadas dimensões "macro", o capitalismo na escala de economia internacional, até as chamadas "micro", as maneiras de viver dos trabalhadores.

Em 1957, escreve com Eric Wolf um texto que se tornaria famoso e onde estaria colocado o conceito de plantation. Trata-se de "Haciendas and plantations in Middle America and the Antilles" (Wolf; Mintz, 1957). No Brasil, plantation, cuja tradução é "plantação", é habitualmente escrita e pronunciada em inglês para se referir a um tipo muito particular de produção agrícola, a grande propriedade monocultora, voltada ao mercado externo, tal como a grande plantação açucareira brasileira. $\mathrm{O}$ conceito foi de tal forma assimilado que aparece em trabalhos para caracterizar a produção brasileira do açúcar sem que os autores reconheçam, ou refiram, a importância de Mintz no aprofundamento do seu significado. Vale lembrar que ele argumentou que a plantation, embora fosse considerada pela teoria econômica uma forma pré-capitalista e pré-industrial, possuía, em vários sentidos, a complexidade das formas capitalistas de organização. Isso se observa tanto nos processos mecânicos envolvidos naquele tipo de produção quanto no tipo de relação com os trabalhadores - escravos, porém com particularidades que os diferenciavam em relação à escravatura mais tradicional -, com o trabalho que exigia uma forma coordenada com aspectos que se assemelhava ao modelo industrial. Argumentava, portanto, que o modelo de plantation do Caribe deveria ser pensado como uma forma nascente de capitalismo e não apenas um novo mercado para a expansão capitalista (Bauser, 1992).

Muitos outros estudos importantes seguiram-se, sendo que dois dos que já citamos anteriormente - Sweetness and power (Mintz, 1985) e Tasting food, tasting freedom (Mintz, 1996) - têm um lugar especial no conjunto de sua obra. Salientamos que, se em um primeiro momento, o autor preocupou-se com a produção e os produtores de açúcar, em Sweetness and power, Mintz também realiza um minucioso exame histórico e antropológico do papel e do significado do açúcar na dieta ocidental.

Como ele mesmo comenta sobre seu livro:

A história do açúcar é longa e complexa demais para tentar resumi-la aqui. Mas é bom sublinhar en passant que o uso da sacarose é relativamente recente na Europa como um todo - talvez um milênio, mas não mais - enquanto que seu uso comum e popular é muito mais recente ainda. Foi somente com o desenvolvimento das plantações no Novo Mundo, e particularmente na segunda metade

Horizontes Antropológicos, Porto Alegre, ano 18, n. 38, p. 373-379, jul./dez. 2012 
do século XVII, que o açúcar começou abaixar de preço na Europa, tornando-se, assim, acessível a outros além de um pequeno segmento da sociedade européia, e mudando de produto medicinal e especiaria para conservante, meio de ostentação, adoçante e, finalmente, alimento. Tentei tratar [em Sweetness an power] da transformação de uma raridade reservada aos príncipes em um prosaico bem de primeira necessidade. (Mintz, 2003, p. 100).

Para nós, conhecer essa história é muito relevante porque o Brasil se notabiliza não apenas como produtor mas como consumidor de açúcar, o que é, inclusive, expresso nas quantidades de açúcar empregado nas receitas dos doces brasileiros. Nesse sentido, o livro de Mintz traz indagações importantes para serem verificadas. Ao mesmo tempo, como nos dias de hoje ocorre uma "demonização" do açúcar, quando alguns especialistas em saúde chegam mesmo a indicar a abolição do açúcar refinado da alimentação, cabe retomar questões levantadas por Mintz para confrontar as diversas perspectivas e concepções elaboradas em torno desse produto.

Para se conhecer a perspectiva do autor, em Tasting food, tasting freedom Mintz (1996, p. 15) diz:

My hope is that they will make people think more about what they eat and why they eat it: about this amazing, everyday activity by which we stay alive. I am myself regularly astonished by what seems to me to be the un-self-reflective manner in which so many Americans eat what they do, under the conditions they do. I wish from time to time that they would do otherwise.

Observa-se assim a contribuição de Sidney Mintz para o espaço disciplinar conhecido como antropologia da alimentação. Para Mintz são muitas as tarefas. Hoje, com a mudança acelerada dos sistemas alimentares, urge tentar compreender como os hábitos e práticas alimentares mundiais estão mudando, como os sistemas e estruturas alimentares, expressos nas "cozinhas", se constroem, o poder da tradição cultural para moldar o comportamento alimentar e o que o futuro reserva.

$\mathrm{Na}$ entrevista publicada nesta edição o autor descreve outros trabalhos de pesquisa que realizou após sua extensa produção que enfocava o açúcar, como, por exemplo, o livro sobre a soja - The world of soy (Du Bois; Tan; Mintz, 2008) - que se confirma como uma obra de muita relevância para o Brasil, e que portanto precisa, urgentemente, de tradução para o português. 
Para concluir, podemos citar um trecho da introdução de seu livro Tasting food, tasting freedom que mostra um pouco do autor Sidney Mintz (1996, p. xi, xviii, tradução nossa, grifo do autor):

Meu pai era um cozinheiro [...] Minhas atitudes em relação à comida e minha estima por ela vieram do meu pai. Este livro nunca teria sido escrito não fosse por causa dele. Minhas melhores memórias sobre ele estão associadas inseparavelmente com a cozinha. Ele não achava que eu era muito bom na cozinha, com certeza. Ele me via cortar uma costela em pé e dizia: "Como é possível que você tenha um Ph.D. e ainda não saiba cortar uma costela em pé?" Eu imagino que ele está em cima atualmente, olhando para baixo e dizendo para um amigo: "Olhe, lá está meu filho. Ele ganha a vida escrevendo sobre comida!"

\section{Referências}

BAUSER, M. Book review: Mintz, Sidney W. Sweetness and power. Michal Bauer is Losing his Mind, 1992. Disponível em: $<$ http://www.michael.bauser. name/19920612T054840Z>. Acesso em: 31 nov. 2011.

DU BOIS, C.; TAN, C. B.; MINTZ, S. (Ed.). The world of soy. Urbana: University of Illinois Press, 2008.

MINTZ, S. W. Cañamelar: the subculture of a rural sugar plantation proletariat (revision of doctoral thesis.) In: STEWARD, J. H. et al. (Ed.). The people of Puerto Rico. Urbana: University of Illinois Press, 1956. p. 314-417.

MINTZ, S. W. Worker in the cane: a Puerto Rican life history. New Haven: Yale University Press, 1960. (Caribbean Series II).

MINTZ, S. W. Caribbean transformations. Chicago: Aldine Press, 1974.

MINTZ, S. W. Encontrando Taso, me descobrindo. Revista de Ciências Sociais, Rio de Janeiro, v. 27, n. 1, p. 45-58, 1984.

MINTZ, S. W. Sweetness and power: the place of sugar in modern history. New York: Viking, 1985. 
MINTZ, S. W. Tasting food, tasting freedom: excursions into eating, culture, and the past. Boston: Beacon Press, 1996.

MINTZ, S. W. Comida e antropologia: uma breve revisão. Revista Brasileira de Ciências Sociais, v. 16, n. 47, p. 31-41, out. 2001. Disponível em: <http:// www.scielo.br/pdf/rbcsoc/v16n47/7718.pdf $>$. Acesso em: 28 fev. 2012.

MINTZ, S. W. O poder amargo do açúcar: produtores escravizados, consumidores proletarizados. Organizado por Christine Rufino Dabat. Recife: Editora Universitária UPFE, 2003.

MINTZ, S. W.; PRICE, R. The birth of African-American culture: an anthropological perspective. Boston: Beacon Press, 1992.

MINTZ, S. W.; PRICE, S. (Ed.). Caribbean contours. Baltimore: Johns Hopkins University Press, 1985.

WOLF, E.; MINTZ, S. W. Haciendas and plantations in Middle America and the Caribbean. Social and Economic Studies, v. 6, n. 3, p. 380-412, 1957. 